\title{
6. The discontinuation of socio-technical systems as a governance problem
}

\section{Peter Stegmaier, Stefan Kuhlmann and Vincent R. Visser}

\subsection{INTRODUCTION}

Abandonment of socio-technical systems occurs more often than one would expect. Companies cancel the development, production or support/ service of devices, technologies and even established systems, for example, in 2011, Siemens exited from building nuclear power plants; and even a state agency like NASA has a long track of stopping systems before or after start-up. ${ }^{1}$ Yet, we know little about how socio-technical systems cease to exist and what it means to discontinue incumbent socio-technical systems actively. ${ }^{2}$ As purposeful transitional change is hard to achieve (Markard et al., 2012), how difficult is it then to abandon existing systems purposefully? Bringing a system to an end might be taken for granted as just a side aspect of change - if one is interested in the entire transition trajectory including the fading out of old and the rise of new systems or their parts. Purposeful discontinuation could none the less turn out to be an essential element of creating a basis for change in general and for implementing it in particular. A better understanding of the conditions, forms, roles, effects and limits of the governance of abandoning longstanding socio-technical systems is a relevant question sui generis, and it can also contribute to a better insight into the governance of systems change in general.

Our point of departure is the observation that the governance of socio-technical systems (Hekkert et al., 2007; Bergek et al., 20083) has preferentially been perceived and associated with advancement and innovation. This may have to do with a bias for progress and continuity in innovation policy and the study of it (cf. Smits et al., 2010; Giddens, 1991, p. 5) or with trust in the often experienced durability of social 
institutions (Simmel, 1897, pp. 667-8; Berger and Luckmann, 1966, pp. 77-8). On the other hand, purposeful abandonment, dismantling, decrease, termination or exit strategies have been the subject of some policy/governance studies so far (Bardach, 1976; de Leon, 1978; Behn, 1978; Brewer, 1978; van de Graaf and Hoppe, 1996, pp. 211-7; Sato, 2002; Sato and Frantz, 2005; Streeck and Thelen, 2005; Bauer, 2009), however they are not dealt with in most of the handbooks on policymaking and governance. The same is true for the limited interest in 'de-institutionalization' in general sociology and organization studies (Berger and Luckmann, 1966, p. 81; Zucker, 1991, p. 105; Hasse and Krücken, 2005, pp. 64-67; Maguire and Hardy, 2009; Stegmaier, 2009, p. 50-1). In Chapter 6, we use the term 'discontinuation' to include all these aspects and dimensions with regards to governance studies.

The governance of the discontinuation of socio-technical systems appears on the political agenda whenever an actor or group of actors (a government, parliament, company or industry association, or group of countries) make a sharp reversal of direction and actively disengage from an on-going policy or governance commitment. In Chapter 6, we first conceptualize the governance aspect of discontinuation processes as a twofold issue: the governance of a 'problem' and a 'problem for governance action' (section 6.2). This leads us to a programmatic list of heuristic views on 'discontinuation governance' (section 6.3). Next, we offer a first empirical sketch, concentrating on one example of discontinuation, the deliberate, purposeful exit from the production or/and usage of incandescent light bulbs (ILB) in the EU within the framework of the European Commission's eco-design directive (European Commission, 2009) $)^{4}$ (section 6.4). Chapter 6 closes with a preliminary set of governance problem dimensions (section 6.5) and a discussion of the overall understanding of 'governance of systems change' (section 6.6).

\subsection{FROM SOLUTIONS TO PROBLEMS: GRASPING THE GOVERNANCE ASPECT OF 'DOING DISCONTINUATION'}

In Section 6.2, we discuss elements of governance theory that are needed for the empirical study of 'discontinuation governance' phenomena. First, we turn to the basic conception of governance processes. Second, we review theory broaching the issue of what we call 'discontinuation governance'. 


\subsubsection{Governance as Process and Practice}

Governance-makers claim to find 'solutions' to 'problems'. Yet, if we want to understand how these solutions come about and materialize, the conflicts and negotiations about and around them, and most importantly how problem-related questions arise, we need to study carefully the questions and problems governance-makers pose themselves in situated interaction (Lerner and Lasswell, 1951; Hisschemöller and Hoppe, 2001, p. 51; Dunn, 2007, pp. 6, 83; Colebatch, 2009, p. 30). ${ }^{5}$ When studying governance and change, we must keep in mind that experienced governance-makers know that what appears as a 'solution' will in turn provoke new practical questions and problems. ${ }^{6}$ We have to understand governance as a process of interpreting and defining problems in such a way that coordination and cooperation is stimulated in a desired manner. Forming a policy and constituting a governance framework 'rests on problematization: ... interpreting the world in a way that makes particular forms of organized response appropriate' (Colebatch, 2009, p. 30). By 'coordination' we mean social action that takes effect aiming at a durable social order, or working together in a well-tuned manner to sustain social order, which can take place in contexts of competition, market, hierarchy, state, network, community, or else, in a variety of forms of activities and interactions and with a variety of mechanisms (cf. Benz, 2006; Schimank, 2002).

Discontinuation, not just as epiphenomenon of broader transitions, needs to be seen as such an interpretive governance process, in the course of which problems (of defining questions and answers, difficulties and possible - solutions) are negotiated and enacted in politicized interactions (cf. Hall, 1986, p. 19; Strauss, 1993, pp. 245-62). 'Governance' is our conceptual perspective for addressing those efforts that aim to initialize or end, align or de-align, with a binding character, concerted action across multiple, competing modes of making, maintaining, and destabilising social order for public or private purposes (drawing on Hoppe, 2010, p. 14 and O'Toole, 2000, p. 278). This conceptual perspective is used as 'a heuristic, borrowed from political science, denoting the dynamic interrelation of involved (mostly organized) actors, their resources, interests and power, fora for debate and arenas for negotiation between actors, rules of the game, and policy instruments applied' (Kuhlmann, 2007, p. 6; cf. Kuhlmann, 2001; Benz, 2006; Braun, 2006). ${ }^{7}$ Whether and how a given governance context is constituted by a more hierarchical or heterarchical structure, within or in-between which arenas (Delemarle and Larédo, 2014, in this book; Strauss, 1993), and, in 
addition, whether state actors or non-state actors drive change (Borrás and Edler, 2014, in this book) has to be answered empirically.

\subsubsection{The Governance of the Discontinuation of a Governance}

The patterns of development of socio-technical systems have been studied broadly (cf. for example, Mayntz and Hughes, 1988), in particular concerning the growth and the governance of large technical systems (Coutard, 1999; Schneider and Bauer, 2009), issues of path dependence (Garud and Karnøe, 2012; Meyer and Schubert, 2007), the transformation of established systems, for example, by regime change (Geels, 2007; Geels and Schot, 2007; Markard and Truffer, 2006; Markard et al., 2012; Konrad et al., 2012), or the change stimulated by new technology (Dolata, 2013). However, the success of a new technology goes hand in hand with the hybridization, fading out, marginalization or failure of existing technologies. The number of studies addressing this kind of development is rather small. Newer conceptualizations of sociotechnical system or regime transitions take 'destabilization' into account (Freeman, 1997; Turnheim and Geels, 2012), but there is no literature to look in-depth at what happens in terms of active, purposeful destabilization. Deters is among, if not the first to analyse the phase-out of the ILB in a case study (Deters 2012), but he has no intrinsic interest in the phase-out governance-making as such, but only as an example for depoliticized EU decision-making.

It is worthwhile to explore the theoretical efforts made to understand termination as a governance problem and process. One area in which we have quite some literature is the 'policy termination' as a side issue in policy studies (van de Graaf and Hoppe, 1996, pp. 221-227; cf. Bauer, 2009, for a detailed overview). ${ }^{8}$ Policy termination may both result from a changed formulation or perception of a policy problem or from a changed formulation or perception of a policy solution (van de Graaf and Hoppe, 1996, pp. 221-227; Hogwood and Gunn, 1984, pp. 250-254). We are interested in the dynamics and underlying processes that lead actors to make a sharp reversal of direction and actively disengage from an on-going policy or governance commitment, as stated before. Action is always linked to prior, on-going and follow-up perceptions of the social reality in which it is (will be or was) conducted (Berger and Luckmann, 1966, pp. 20-46). Termination in this sense means observing an environment in which discontinuity is, for policymakers, the obvious thing to happen or to make happen, or at least a possible option.

Drawing upon the latter terminology, 'policy dismantling' has recently been introduced by Bauer et al. as an analytical notion for 'a distinctive 
form of policy change, which involves the cutting, reduction, diminution or complete removal of existing policies' (Bauer and Knill, 2012, p. 31). The authors see their analytical framework as a contribution to the analysis of policy change. They focus on politicians' preferences and dismantling strategy choices in the context of external factors, institutional constraints and opportunities, and situational factors in light of outcomes and effects (Bauer and Knill, 2012, p. 32). Yet, when it comes to the discontinuation of complex socio-technical systems it is not enough to observe politicians as central actors, we have to take a broader spectrum of actors into account. Also one has to trace the development of a discontinuation trajectory rather than limiting the view to pre-defined sets of 'factors' and 'variables' in a rather static framework. The understanding of a specific combination of actions, structures, situations and circumstances are, in our view, the result of the investigation rather than pre-defined categories.

Our research leads us to expand on the 'termination' or 'dismantling' concept further in terms of a 'governance of termination'. In paraphrasing van de Graaf's and Hoppe's notion of 'policy termination' (1996, pp. 21-7), we see 'discontinuation' as a particular way of solving a governance problem which is the result of a changed perception and formulation of a governance problem. This is a twist missed in other literature (Bauer et al., 2012; Ferry and Bachtler, 2013): the governance efforts that are necessary to end the governance structures and processes underpinning the old system are of equal importance in order to see the full picture of system's discontinuation. This does not necessarily mean the termination of a policy/governance only, but also the governance and policies that accompany the ending and the aftercare of what cannot be fully dismantled (like nuclear waste, or DDT for vector control which is still allowed to be used after the worldwide ban of DDT for agricultural use under the Stockholm convention in 2004; cf. Stockholm Convention 2009). The analysis shows that to terminate a governance means, most often, to start a new one dedicated to discontinuation. The governance efforts to end a socio-technical system may even last longer than the governance of the socio-technical system that has been terminated.

\subsection{TOWARDS A TENTATIVE HEURISTIC FOR THE STUDY OF DISCONTINUATION GOVERNANCE}

The key question of Chapter 6 is: 'How to discontinue incumbent socio-technical systems?' We will now turn to the case of incandescent light bulbs (ILB) as a first illustration, working with a tentative research 
heuristic that will be revised and improved in the course of progressing empirical case research. The heuristic starts from a number of key orientations on how socio-technical systems are brought to a halt:

1. We turn away from the normal focus of studies of socio-technical systems that emphasise progress and innovation, institutionalization and continuity, and turn to ending phenomena: processes and acts of destabilization, deinstitutionalization, deconstruction, dismantling, termination and related strategies and structures in socio-technical contexts.

2. Analytically and empirically, we focus on the patterns of discontinuity in the governance of socio-technical systems. From this point of view, innovation, replacing technologies and progress may appear in a new light.

3. We focus on discontinuation as a purposeful action sui generis (in socio-technical contexts), be it setting change in motion (enacted discontinuation) or seizing on prevailing developments of change (emergent discontinuation); be it active governance or the broader regime context.

4. We analyse discontinuation as a problem of interpretation and action for governance makers. We assume that discontinuation achievements are both a result of a changed formulation or perception of a governance problem as well as of a governance solution. This means that those making 'discontinuation governance' work always need to grasp the problem personally and collectively (intersubjectively) - understand, communicate and negotiate the problem structure individually and together. This encompasses both the perception of facts and of values, of what is the case and what ought to be the case.

5. We take into consideration both the discontinuing of a governance (of a socio-technical system) and the governance of the discontinuing (of a socio-technical system). Both might refer to existing, or lead to new forms of, institutionalising and legitimising governance. Both might lead to the dismantling and/or expansion of governance (cf. Bauer and Knill, 2012, p. 33).

\subsection{THE CASE OF THE INCANDESCENT LIGHT BULB}

Several policy initiatives for the phasing-out of the energy-inefficient light bulb (ILB) have been introduced recently around the globe (Edge and McKeen-Edwards, 2008, pp. 2-7). In 2009, after years of discussion 
in EU member states, in the European Parliament and the European Commission, an EU directive was presented for the gradual phasing-out of traditional (or so-called 'energy inefficient') household lighting (European Commission, 2009). This process is described in some detail below: drawing on a pilot study by Visser (2012), in which the agenda setting for governance changes ('establishing the problem') was reconstructed from policy documents available online. These documents were analysed with regard to the communications on all sorts of problems faced by the proponents of the ILB ban.

The phase-out of the ILB technology through EU regulation 244/2009, based on the Eco-Design of Energy-Using Products Directive 2009/125/ EC, started in 2009. Immediate discontinuation applied only to generalpurpose, non-directional 100 watt incandescent bulbs. For the rest, the permitted watt limit was gradually reduced while the efficiency levels were raised step-by-step until September 2012. Although many new types of energy-efficient light bulbs had already entered the market, the ILB was the one most often used for domestic lighting until it came into disrepute because of the energy waste attributed to its technology. This negative attribution occurred in the context of redefining political and technical criteria for lighting technology. This was a process of mutual adoption that was part of a 'governance dispositif' in which both public actors (for example EU commission, European Parliament, member state parliaments) and private actors (for example lobby organizations of the lighting industries, NGOs) played a role. The formation of such a dispositif requires the cognitive and political-strategic alignment of actors in terms of problem perception ('making sense together') and coordinated action (forming an advocacy coalition).

In the case of domestic lighting, the governance trajectory of the eco-design regulation for the discontinuation of the ILB started with an omnipresent push for the phasing-out of the ILB in order to stimulate the use of energy-efficient light bulbs. The agenda-setting process of this discontinuation had a long history and involved many different actors, such as the lighting industry, NGOs and political parties on multiple levels. Ultimately, the proposed ban of ILBs was pushed bottom-up by different interest groups and was part of a global policy diffusion. Important driving factors for this policy diffusion were the low costs of the discontinuation governance and the relative ease of its implementation due to the widespread support from industry and environmentalists (Edge and McKeen-Edwards, 2008, pp. 2-7). The main argument for a policy to ban the use of ILB, at least in publicly available documentation, was based on the notion of sustainability, which mobilized a wide public 
consensus. As a consequence, the European Lamps Companies Federation (ELC) considered proposing to phase out the ILB before there even was any regulation (ELC, 2007). At the same time, several member states introduced or discussed first governance initiatives to phase out ILBs (European Parliament, 2007).

The governance process for a final regulation on the discontinuation of the ILB was mainly facilitated and structured by the European Commission by embedding it in the eco-design directive (Visser, 2012). The eco-design directive (European Union, 2005, 2009) is a framework regulation for improving the environmental performance of energy-using products through eco-design requirements. Eco-design requirements aim to set new standards for the design of a product to improve its environmental performances, or to improve the supply of information on its environmental aspects. This eco-design framework operates on the supranational level to overcome separate national legislation and to preserve the free movement of goods. For domestic lighting, an ecodesign regulation was proposed with the emphasis on improving the energy-efficiency performance of lamps and their environmental performances.

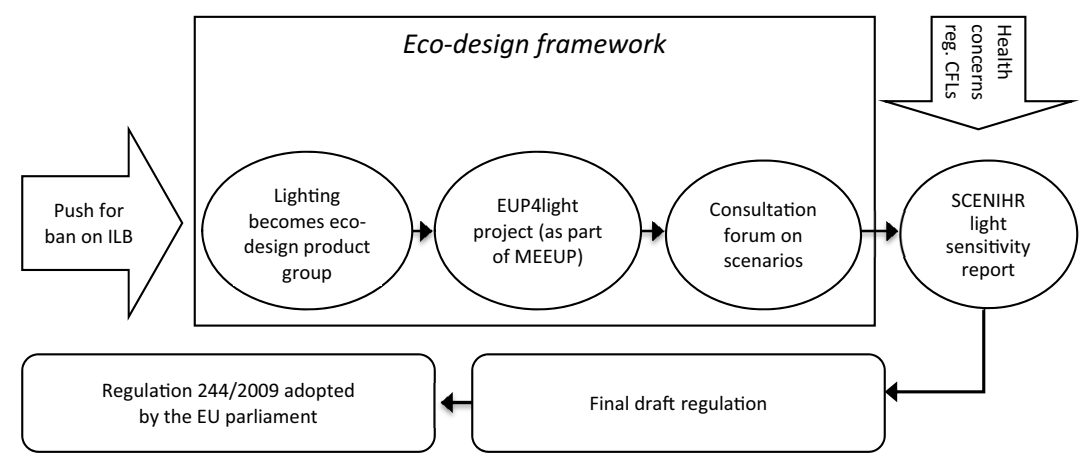

Source: Based on Visser (2012, p. 17).

Figure 6.1 The EU governance trajectory of the ILB discontinuation

Within the eco-design framework, the governance-making process of eco-design requirements was facilitated and pre-structured by the European Commission with the help of fixed approaches, such as MEEuP', and additional formats of combined expertise and governance during the policy-making trajectory, such as the so-called SCENHIR report. After domestic lighting was recognized as a product group, the second step within the eco-design framework included an open stakeholder project 
(Vito, 2009b). This project facilitated stakeholders' participation in the development of scenarios for the phasing out of inefficient lighting and set eco-design requirements. To be able to formulate eco-design requirements for domestic lighting, the European Commission installed the EUP4light project to carry out a technical, environmental and improvement analysis of domestic lighting in a fixed format (Vito, 2009a). In the aftermath of the study, the Commission proposed different scenarios for the phasing-out of inefficient domestic lighting (European Commission, 2009). During the third phase of the eco-design trajectory, a closed stakeholder participation project was set up that included experts and representatives of member states to discuss the formulated scenarios. This was called the Consultation Forum and enabled the representatives of member states and invited experts to discuss possible eco-design requirements and propose a final discontinuation scenario (Consultation Forum, 2008). After these scenarios were discussed in the Consultation Forum, the Commission proposed a draft regulation to the European Parliament. Before this draft regulation could be amended, however, pressure from societal actors who were concerned about the consequences of the use of energy-efficient lighting led to an additional step in the governance-making trajectory, namely the preparation of a "light sensitivity report' (SCENIHR, 2008). This report in turn concluded that the proposed health concerns were mostly ungrounded. This paved the way for the Commission to draft the regulation. After some amendments by the European Parliament, the discontinuation of the ILB was introduced and implemented in the member states (European Commission, 2009). Figure 6.1 provides a graphical model of the governance-making trajectory of the discontinuation of the ILB.

\subsection{PRELIMINARY SET OF GOVERNANCE PROBLEMS IN THE ILB BAN CASE}

Against the background of this illustration and our earlier conceptualization, we can now further distinguish six procedural dimensions of dedicated discontinuation governance (not to be understood as subsequent steps) and related core governance problems ${ }^{10}$ :

\subsubsection{Aligning Problem Perceptions through Increasingly Structured Interaction}

The increasingly structured interaction of a variety of actors (the lighting industry, their associations, NGOs, EU commission, EU parliament, 
parties, member countries, and so on) became the driving forces for changing or establishing the problem perception. Their task was to raise the issue in the first place and to find common ground for understanding the policy problem. 'Making sense together' (Hoppe, 2010, pp. 167-8) was essential in this phase for politically and technically redefining the lighting technology and attributing energy waste to the old type of bulbs. Hence, while policy-makers mainly looked at the amount of energy wasted through the usage of the old bulbs, many critics also pointed at the energy waste during the production of the new bulbs. Meanwhile, other ambiguities had to be managed (Choo, 2006, pp. 5-8, 75-125), for example over concerns such as the mercury contained in energy saving bulbs. Representatives from various pools of expertise with different kinds of knowledge had to be mobilized: technical and legal experts, policy experts in national, EU, NGO and corporate realms, and so on. Still, this phase was rather diffuse, as various global and regional interest groups contributed more or less explicitly to the formation of the ILB ban and energy saver introduction dispositif.

\subsubsection{Setting and Keeping the Problem on the Political Agenda...}

The task throughout the whole trajectory was to set the new problem perception and keep it on the political agenda, whereby getting domestic lighting recognized as a product group within the eco-design framework proved to be the main problem. The actual political plan that had to be carried through in collaboration with and against others was described as a 'continuing, contested and ambiguous process' of 'agenda construction' (Colebatch, 2009, p. 91). Nonetheless, one could argue that this process provided the platform for a debate about the policy level to which the problem would have to be attributed; and at the end of the day, the initiators reached their aim when the European Commission decided to approach the ILB via the Eco-design directive. Interestingly, citizens mobilized against the ban only after the decision was taken by way of petitions to the European Parliament in 2009 and 2010, as well as with pop-cultural means of information, protest, and polemization (with web sites and even a documentary film called 'Bulb Fiction').

\subsection{3 ... In Combination with Building, Maintaining and Changing Advocacy Coalitions}

Simultaneously, advocacy coalitions had to be established and maintained. Only through a broader alliance of actors, which were partially changing over time, could the waste of energy be attributed to the old 
type of bulbs. Because the ILB policy-making was referring to the eco-design directive, it was possible to make use of the existing policymaking-infrastructure for setting up new eco-design-rules.

\subsubsection{Mobilising Existing/New Governance Instruments}

Overall, the entire eco-design framework is, in a sense, a tool for managing and processing governance projects as, in our case, is the replacement of an old lighting technology with various new ones. Several specific existing and new governance instruments were mobilized in this process: initially the MEEuP (Methodology for the Ecodesign of Energyusing Products) was followed as the standard procedure. Later, and in accordance to the SCENIHR scheme, the so-called 'Light sensitivity report' by the 'Scientific Committee on Emerging and Newly Identified Health Risks' was added. For the assessment, another specific instrument called the EU4light project was used.

\subsubsection{Politically Binding and Legitimate Decision-making}

The phase-out of ILBs and the introduction of CFLs (compact fluorescent lamps, commonly called 'energy saving lamps') is an example of politically binding and legitimate decision-making through which a regulation project was adapted within the existing legal framework, which in turn was further developed with a new specific regulation. This way, using the eco-design framework, the general eco-design directive for all sorts of energy using products could be developed into a specific eco-design regulation for domestic lighting products for all EU member states.

\subsubsection{Governing Socio-technical Aftercare}

In general, abandoned socio-technical systems do not vanish completely and some continued governance effort is necessary long after their exit (for example nuclear waste and DDT for vector control). In case of the ILBs, lamps that are used for special purposes in medical or design settings are still allowed, which means that an ongoing dedicated governance structure is required. As the ILB is concerned, one could interpret the phase-out stage as an initial aftercare effort. The step-bystep reduction of wattage was necessary in order to allow time for the new, not yet fully functioning and marketable replacement products to mature, and to make users aware of the advantages of efficient lighting. The gradual production ban is a form of managing the end-of-life period 
after the exit decision has been taken. Having reached the last step, the aftercare currently consists of two main elements. First, it deals legally, politically and technically with the remaining kinds of old bulbs that are still permitted and, often enough, piled up for sale after the implementation of the production ban; second, it manages the soon-to-be implemented exit from some of the replacement products, for example the CFLs, which contain mercury and therefore will have to be banned until 2020, according to the 2013 Minamata Convention.

The above set of dimensions will be further developed on the basis of a number of further case studies of different socio-technical systems.

In Chapter 6, we were able to identify two conceptual innovations for the study of discontinuation governance, (1) the sense-making and problem construction before the actual agenda work, as well as (2) the relevance of aftercare:

- A new problem perception is a necessary prerequisite for change, because if the problem perception remains unchanged, any call for action is perceived as futile and remains without consequence (other than unnoticed shifts).

- Aftercare is a necessary prerequisite for change in so far as it allows unsolved issues of a governance process to be dealt with. It helps to avoid fraying and to control the loose ends of 'undead' regime and system parts.

\subsection{CONCLUSIONS: ANALYSING THE GOVERNANCE OF DISCONTINUATION}

The presented research approach towards the governance of the discontinuation of socio-technical systems is still under construction, as has been repeatedly emphasized in this paper. Yet, with a serious note of caution, we can assume that:

(1) discontinuation indeed takes place, and it does so in a highly complex context - technically as well as socially - (the DDT ban, e.g., seems to be situated within a rather unchanged framework of continuity of crop protection in general ${ }^{11}$ ) and;

(2) in most cases, discontinuation has to cope with quite some resistance to dedicated, forceful change (think of the exit from nuclear energy production with all the many backward and forward movements in countries like Germany and Japan); 
(3) the ILB phase-out is an exceptional case in which resistance was relatively small and coalitions among actors broad.

Unsurprisingly, in spite of some strong political will, institutional inertia and vested interests are prevalent. We suggest that discontinuation achievements are both a result of a changed formulation or perception of a governance problem as well as of a governance solution: discontinuation agents, if successful, have to manage the unbundling of forces and the dismantling of existing structures in order to overcome inertia of current systems and networks. They have to find and use instruments and resources (Frantz, 2002), as well as interpret and try to affect on-going processes (Rein and Schön, 1993).

In contrast to, for example, 'discontinuity' as a market phenomenon (Utterback, 2003) and 'destabilization' as a regime transition phenomenon (Turnheim and Geels, 2012), our attention is firmly focused on dedicated governance for the discontinuation of established systems - in other words, on 'discontinuation' as purposeful governance action sui generis in socio-technical contexts. By coining the notion 'discontinuation' we indicate the process orientation of our research focus. Smith et al. also started looking into this direction when they developed their typology of transition contexts including highly coordinated forms: committed processes driven internally (endogenous renewal) or externally (purposive transition, quite similar to the idea of a transition management project) (Smith et al., 2005, pp. 1498-1502). A key question is what discontinuation means as a problem of interpretation and action for policy-makers (cf. Hoppe, 2010; Colebatch, 2009).

The phase-out of the incandescent light bulb technology through the EU regulation 244/2009, based on the Eco-Design of Energy-Using Products Directive 2009/125/EC, started in the EU in 2009 (Visser, 2012; Stegmaier et al., 2012; Edge and McKeen-Edwards, 2008). Looking at the governance process, it can be noted that the ILB governance problem is fully under control or 'structured' in the sense that currently there is no open process, but the knowledge and value questions have been settled. Governance actors treat the case as unproblematic. Thus the European Union, together with Switzerland and Australia, follows four years after Brazil and Venezuela who were the first to start phasing ILB out in 2005. Argentina and Russia are planning phase-outs in 2012, and the United States, Canada, Malaysia and South Korea in 2014. The phase-out appears disruptive in several countries. After some pioneers went ahead, increasingly coordinated action was organized, most formally designed within a regulatory framework, partially dedicated to the ILB ban, partially a general one for diverse products. We would like to emphasize 
the interplay of internal and external drives. In the ILB case, the discontinuation is mainly legitimized by pointing at the inefficiency of the 'old technology' (internal driver), although finally an external driver was needed to realise the transition (the eco-design directive); all promised new technology was not yet available at the begin of the ban in 2009, such as LED lamps, which were not yet ready for the market up until 2011. ${ }^{12}$

The crosscutting basic assessment of what the problem of 'discontinuation governance' is and how the structures of knowledge and agreement are developed, both under change conditions and under changing conditions, also helps to concretize the following three pillars developed by Borrás and Edler (2014), because for each pillar we have to reveal the practical and fundamental movens, the tensions and ways of dealing with an issue from a governance perspective.

First, Borrás and Edler ask what and who drives or inhibits change. They subscribe to the idea that agents (individual and collective actors) navigate in more or less complex environments and struggle for aligning positions and resources for change, while institutions might provide opportunity structures or thresholds for change activity (Borrás and Edler, 2014). Indeed, is it a core question for our investigation into 'discontinuation governance' which framings institutions and which reframing actors suggest; how much room for manoeuvre in terms of political bargaining and negotiation is available; how structures and acts of power and interest are mobilized; and which role normal actors, on the one hand, and particularly visionary or entrepreneurial governance activists, on the other hand, may play (Smith et al., 2005; Smith and Stirling, 2010). Our dimensions 'dynamics' and 'actors' echo such a focus on opportunity structures and capable agents. Crucially, we are able to show empirically how both actors observing institutions, on the one hand, and institutions observing actors, on the other hand, actually interpret and frame opportunities, reasons, utility and meaningfulness of fostering (or hindering) change, and which often ambiguous patterns of relevance, motives, interests and experiences they associate with change, or with discontinuation in particular.

This is linked, second, to 'policy instruments', our dimension that covers the enquiry into how governance is executed. More specifically, we need to further investigate how instruments are constructed and designed, how they work or do not work, and how they interact with other, non-instrumental governance (Borrás and Edler, 2014). There are certainly economic and regulatory instruments used for discontinuation governance, and further research will show what they are supposed to do and what they can do - instruments between nudging and forcing change 
of behaviour. The question for further investigation is how far they combine economic and legal aspects. Besides, one should ask, who does actually instrumentalize whom, when domestic lighting producers push ILBs into the eco-design framework, while the European Commission takes this as an opportunity to set an example for active EU level environmentalism, by putting pressure on the lighting industries to innovate their ILB-replacing products more quickly than planned, and on the consumer public to change their household lighting habits towards more efficient technology (while there are still some groups denying the need for using efficient lighting because they focus on the burdens of using new lamps and their electronic waste). Furthermore, it needs to be investigated which instruments (and other governance aspects) are part of which broader strategy or governance style (mode). Our case study indicates so far that governance instruments and strategies embrace far more than state actors.

Third, why is change accepted (or not) and how is legitimacy created? This is the third dimension on which Borrás and Edler put emphasis (2014). We differentiate between the aspects of regulation and justification and focus explicitly on the social process and practice character of seeking, finding or loosing legitimacy at the input and/or output stage. This way, we direct a clear empirical focus, not a normative one, on governance and legitimacy. We ask how legitimacy is claimed, criticized, lost and won, and how it explains the institutional order (Berger and Luckmann, 1966, p. 93), how the 'legitimate order' (Weber, 1978) is empirically constituted, in which arenas and in which frame of reference. When discontinuation takes time, it is only logical that governance practitioners and we observers have to check for throughput legitimacy, too - this is for procedures on which enduring legitimacy is built (cf. Luhmann, 1969) and for the ups and downs of legitimacy. The crisis moments in the preparation of the ILB ban, when health issues about the replacing CFLs were brought up, in a striking way show how legitimation needs to be maintained especially during the process.

Change and discontinuation require actors to learn to adapt to altering or altered states of what they know and value. Governance is not only coordination, negotiation and (perhaps, to some extent) collaboration in a technical manner - it builds on actors' understanding of their world and how they get socialized into it. If the perceived world is changing, 'problems' arise and institutions that are taken for granted get destabilized or are actively dismantled by those who have defended them up to now, entire frameworks of reference have to be readjusted, new routines in dealing with the conditions of political, economic and technical behaviour have to be found, and prior decisions and beliefs reconsidered. 
In short, the governance of change in socio-technical and innovation systems both has to cope with and is an object of discontinuation.

\section{ACKNOWLEDGEMENTS}

Chapter 6 has benefited appreciably from comments by Jakob Edler and Susana Borrás.

\section{NOTES}

1. For instance, the Space Shuttle system programme 1972-2011 or the Project Apollo 1961-72 that were stopped after years of usage, whereas the permanent moon base, aka 'Lunar outpost', was halted in 2010 after four years before being put to use. Considering how difficult it turns out to be for Microsoft to discontinue Windows XP (by making it impossible to use it safely, for instance), it seems that sometimes discontinuation precedes change.

2. However, the governance of the discontinuation of socio-technical systems has only recently been put on the agenda of social scientific research in an explicit manner (Stegmaier et al., 2012; Turnheim and Geels, 2012). Chapter 6 results from the research project 'Governance of Discontinuation of Sociotechnical Systems' (DiscGo), carried out by a consortium consisting of four research groups at SPRU Brighton, TU Dortmund University, IFRIS Paris and University of Twente, funded from 2012-2015 through an Open Research Area (ORA) scheme grant by NWO, DFG, ESRC and ANR.

3. This has some overlap with the body of literature on the 'regime' notion (cf. Geels and Schot, 2007; Nelson and Winter, 1982).

4. The Ecodesign Directive 2009/125/EC (extension to energy related products) followed the Amending Directive (2008/28/EC) and the initial version of the Ecodesign Directive (2005/32/EC).

5. In policy studies, this has led to coining the notions of 'wicked problems' and 'problem structuring' (Rittel and Webber, 1973; Dunn, 2007; Hoppe, 2010).

6. This does not imply that our problem-oriented approach sees social science as a problem solver.

7. Besides policy-makers we include all kinds of actors as governance-makers, such as industry, NGOs, distributors, dealers, as well as simple users and organized usergroups. In the case of the ILB, the industry itself had already organized some plans and strategies to fade out the ILB before the European commission actively pursued the ban.

8. The issue at stake here - the submergence (as the opposite of emergence) and abandonment (actively exiting) of a governance or an object of governance - has also been referred to as 'retrenchment' elsewhere (Pierson, 1994).

9. MEEuP stands for 'Methodology Study for Ecodesign of Energy-using Products' (see http://ec.europa.eu/enterprise/policies/sustainable-business/ecodesign/method ology/index_en.htm).

10. In Visser (2012) and Visser and Stegmaier (2014) we also look at the socio-technical problems of the phasing out (challenges for industry and burdens for users, burdens for infrastructure) and the way these challenges also had to be tackled by the choice of governance instruments. We call this the 'socio-technical regime' side of the coin. 
11. This observation is currently developed by Pierre-Benoît Joly and colleagues in one of the discontinuation governance projects.

12. Besides, we also observe that sometimes 'old technologies' (for example LPs, that is 'long play' records) are reintroduced - not only by the public and in for a niche market, but also by some technology start-ups that use an old technology or technological idea, solve the old technical problems and reintroduce the technology in a new form. But this is worth another investigation of its own right.

\section{REFERENCES}

Bardach, E. (1976), 'Policy termination as a political process', Policy Sciences, 7 (2), 123-131.

Bauer, M. W., A. Jordan, C. Green-Pedersen and A. Héritier (eds) (2012), Dismantling Public Policy: Preferences, Strategies, and Effects, Oxford: Oxford University Press.

Bauer, M. W. and C. Knill (2012), 'Understanding policy dismantling: An analytical framework', in M. W. Bauer, A. Jordan, C. Green-Pedersen and A. Héritier (eds) (2012), Dismantling Public Policy, Preferences, Strategies, and Effects, Oxford: Oxford University Press, pp. 30-51.

Bauer, M. W. (2009), 'The policy termination approach: Critique and conceptual perspectives', Lehrstuhl für Politik und Verwaltung Working Paper Series (WP \#1/2009), Berlin: Lehrstuhl für Politik und Verwaltung, accessed 22 July 2011 at www.sowi.hu-berlin.de/lehrbereiche/politikundverwaltung/wps/workingpaper-1.

Behn, R. D. (1978), 'How to terminate a public policy: A dozen hints for the would-be policy terminator', Policy Analysis, 4 (3), 393-414.

Benz, A. (2006), 'Governance in connected arenas - Political science analysis of coordination and control in complex control systems', in D. Jansen (ed), New Forms of Governance in Research Organizations. From Disciplinary Theories towards Interfaces and Integration, Heidelberg and New York: Springer, pp. 3-22.

Bergek, A., S. Jacobsson, B. Carlsson, S. Lindmark and A. Rickne (2007), 'Analyzing the functional dynamics of technological innovation systems: A scheme of analysis', Research Policy, 37, 407-429.

Berger, P. L. and T. Luckmann (1966), The Social Construction of Reality. A Treatise in the Sociology of Knowledge, Garden City, New York: Doubleday.

Borrás, S. and J. Edler (2014), 'The governance of change in socio-technical systems: Some pillars for a conceptual framework', in S. Borrás and J. Edler (eds), The Governance of Systems Change, Cheltenham, UK and Northampton, MA, US: Edward Elgar.

Braun, D. (2006), 'Delegation in the distributive policy arena: The case of research policy', in F. Gilardi and D. Braun (eds), Delegation in Contemporary Democracies, London: Routledge, pp. 146-170.

Brewer, G. D. (1978), 'Termination: Hard choices, harder questions', Public Administration Review, 38 (4), 338-344. 
Choo, C. W. (2006), The Knowing Organization: How Organizations Use Information to Construct Meaning, Create Knowledge, and Make Decisions, Oxford: Oxford University Press.

Colebatch, H. (2009), Policy, Berkshire: Open University Press.

Consultation Forum (2008), 'Annex 2: Working document on possible ecodesign requirements for general lighting equipment', accessed 21 April 2012 at http://ec.europa.eu/energy/efficiency/ecodesign/doc/forum/2008-03-28.zip.

Coutard, O. (2002), The Governance of Large Technical Systems, London: Routledge.

Delemarle, A. and Ph. Larédo (2014), 'Governing radical change through the emergence of a governance arrangement', in S. Borrás and J. Edler (eds), The Governance of Systems Change, Cheltenham, UK and Northampton, MA, US: Edward Elgar.

Deters, H (2012), 'Arenas and Bargaining Dynamics in EU Efficiency PolicyMaking', paper presented at the $42^{\text {nd }}$ UACES Annual Conference in Passau, 5 September 2012

Dolata, U. (2013), The Transformative Capacity of New Technologies. A Theory of Sociotechnical Change, London and New York: Routledge.

Dunn, W. N. (2007), Public Policy Analysis: An Introduction, New Jersey: Pearson/Prentice Hall.

Edge, J. and H. McKeen-Edwards (2008), 'Light bulbs and bright ideas? The global diffusion of a ban on incandescent light bulbs', paper presented at the 80th Annual Conference of the Canadian Political Science Association, University of British Colombia, 5 June 2008, accessed 15 June 2013 at www.cpsa-acsp.ca/papers-2008/Edge-McKeen-Edwards.pdf.

European Commission (2009), 'Regulation 244/2009: Implementing Directive 2005/32/EC of the European Parliament and of the Council with regard to ecodesign requirements for non-directional household lamps', accessed 14 February 2012 at http://eur-lex.europa.eu/LexUriServ/LexUriServ.do?uri= OJ:L:2009:076:0003:0016:EN:PDF.

European Lamp Companies Federation (ELC) (2007), 'The ELCs proposal for domestic lighting', accessed 23 April 2012 at http://www.elcfed.org/ documents/2.\%20Phase-out\%20proposal.pdf.

European Parliament (2007), 'E-1184/07: Written question', accessed 24 April 2012 at www.europarl.europa.eu/sides/getDoc.do?pubRef=-//EP//TEXT+ WQ+

E-2007-1184+0+DOC+XML+V0//EN.

European Union (2009), 'Directive 2009/125/EC for establishing a framework for the setting of ecodesign requirements for energy-related products (recast)', accessed 14 February 2012 at http://eur-lex.europa.eu/LexUriServ/LexUri Serv.do?uri=OJ:L:2009:285:0010:0035:en:PDF.

European Union (2005), 'Directive 2005/32/EC for establishing a framework for the setting of ecodesign requirements for energy-using products', accessed 14 February 2012 at http://eur-lex.europa.eu/LexUriServ/LexUriServ.do?uri=OJ: L:2005:191:0029:0029:EN:PDF.

Ferry, M. and J. Bachtler (2013), 'Reassessing the concept of policy termination: The case of regional policy in England', Policy Studies, 34 (3), 255-273.

Frantz, J. E. (2002), 'Political resources for policy terminators', Policy Studies Journal, 30, 1, pp. 11-28. 
Freeman, C. (1997), 'The diversity of national research systems', in R. Barré, M. Gibbons, J. Maddox, B. Martin, P. Papon (eds), Science in Tomorrow's Europe, Paris: Economica International, pp. 183-194.

Garud, R. and P. Karnøe (2012), Path Dependence and Creation, Hove: Psychology Press.

Geels, F. W. (2007), 'Transformations of large technical systems: A multilevel analysis of the Dutch highway system (1950-2000)', Science, Technology \& Human Values, 32 (2), 123-149.

Geels, F. W. and J. Schot (2007), 'Typology of sociotechnical transition pathways', Research Policy, 36 (3), 399-417.

Giddens, A. (1991), The Consequences of Modernity, Cambridge: Polity.

Graaf, H. v. d. and R. Hoppe (1996), Beleid en Politiek. Een Inleiding tot de Beleidswetenschap en de Beleidskunde, Bussum: Coutinho.

Hall, P. (1986), Governing the Economy: The Politics of State Intervention in Britain and France, New York: Oxford University Press.

Hasse, R. and G. Krücken (2005), Neo-Institutionalismus, Bielefeld: transcript.

Hekkert, M. P., R. A. A. Suurs, S. O. Negro and S. Kuhlmann (2007), 'Functions of innovation systems: A new approach for analyzing technological change', Technological Forecasting and Social Change, 74 (4), 413-432.

Hisschemöller, M. and R. Hoppe (2001), 'Coping with the intractable controversies: The case for problem structuring in policy design and analysis', in $\mathrm{M}$. Hisschemöller, R. Hoppe, W. N. Dunn and J. R. Ravetz (eds), Knoweldge, Power, and Participation in Environmental Policy Analysis, New Brunswick: Transaction, pp. 47-72.

Hogwood, B. W. and L. A. Gunn (1984), Policy Analysis for the Real World, Oxford: Oxford University Press.

Hoppe, R. (2010), The Governance of Problems: Puzzling, Powering and Participation, Bristol: Policy.

Konrad, K., J. Markard, A. Ruef and B. Truffer (2012), 'Strategic responses to fuel cell hype and disappointment', Technological Forecasting \& Social Change, 79 (6), 1084-1098.

Kuhlmann, S. (2007), 'Governance of research - Nine comments on Arthur Benz', in D. Jansen (ed), New Forms of Governance in Research Organizations: From Disciplinary Theories towards Interfaces and Integration, Heidelberg and New York: Springer, pp. 23-25.

Kuhlmann, S. (2001), 'Future governance of innovation policy in Europe - Three scenarios', Research Policy, 30, 953-976.

deLeon, P. (1978), 'A theory of policy termination', in J. V. May and A. B. Wildavky (eds), The Policy Cycle, Beverly Hills: Sage, pp. 279-300.

Lerner, D. and H. D. Lasswell (1951), The Policy Sciences: Recent Developments in Scope and Methods, Stanford: Stanford University Press.

Luhmann, N. (1969), Legitimation durch Verfahren, Neuwied and Berlin: Luchterhand.

Maguire, S. and C. Hardy (2009), 'Discourse and deinstitutionalization: The decline of DDT', Academy of Management Journal, 52 (1), 148-178.

Markard, J. and B. Truffer (2006), 'Innovation processes in large technical systems: Market liberalization as a driver for radical change', Research Policy, 35 (5), 609-625. 
Markard, J., R. Raven and B. Truffer (2012), Sustainability transitions: An emerging field of research and its prospects, Research Policy, 41, 955-967.

Mayntz, R. and T. P. Hughes (1988), The Development of Large Technical Systems, Frankfurt/M.: Campus.

Meyer, U. and C. Schubert (2007), 'Integrating path dependency and path creation in a general understanding of path constitution: The role of agency and institutions in the stabilisation of technological innovations', Science, Technology \& Innovation Studies, 3, 23-44.

Nelson, R. and S. G. Winter (1982), An Evolutionary Theory of Economic Change, Cambridge, MA: Harvard University Press.

O'Toole, L. J. (2000), 'Research and policy implementation: Assessments and prospects', Journal of Public Administration Research and Theory, 10 (2), 263-288.

Pierson, P. (1994), Dismantling the Welfare State?, Cambridge: Cambridge University Press.

Rein, M. \& Schön, D. A. (1993), 'Reframing policy discourse', in: F. Fischer \& J. Forrester (eds), The argumentative turn in policy analysis and planning, Durham/London: Duke UP, pp. 145-166.

Rittel, H. W. J. and M. M. Webber (1973), 'Dilemmas in a general theory of planning', Policy Sciences, 4 (2), 155-169.

Sato, H. (2002), 'Abolition of leprosy isolation policy in Japan: Policy termination through leadership', Policy Studies Journal, 30 (1), 29-46.

Sato, H. and J. E. Frantz (2005), 'Termination of the leprosy isolation policy in the US and Japan : Science, policy changes, and the garbage can model', BMC International Health and Human Rights, 5 (3), 1-16.

Stockholm Convention (2009), 'Stockholm convention on Persistent organic pollutants', Stockholm: The Secretariat of the Stockholm Convention, accessed 26 June 2013 at http://chm.pops.int/Convention/ConventionText/ tabid/2232/Default.aspx.

Schneider, V. and J. M. Bauer (2009), 'Von der governance - zur komplexitätstheorie. entwicklungen der theorie gesellschaftlicher ordnung', in J. Weyer and I. Schulze-Schaeffer (eds), Management Komplexer Systeme. Konzepte für die Bewältigung von Intransparenz, Unsicherheit und Chaos, München: Oldenbourg, pp. 31-53.

Scientific Committee on Emerging and Newly Identified Health Risks (SCENIHR) (2008), 'Light sensitivity', Brussels: Health \& Consumers DG, Directorate C: Public Health and Risk Assessment, Unit C7 - Risk Assessment, Brussels, European Commission, accessed 19 July 2013 at http://ec. europa.eu/health/archive/ph_risk/committees/04_scenihr/docs/scenihr_o_019. pdf.

Simmel, G. (1897), 'The persistence of social groups: I', American Journal of Sociology, 3, 662-698.

Smith, A. and A. Stirling (2010), 'The politics of social-ecological resilience and sustainable socio-technical transitions', Ecology and Society, 15 (1), 11.

Smith, A., A. Stirling and F. Berkhout (2005), 'The governance of sustainable socio-technical transitions', Research Policy, 34, 1491-1510.

Schimank, U. (2002), Handeln und Strukturen. Einführung in die akteurstheoretische Soziologie, Weinheim and München: Juventa. 
Smits, R. E., S. Kuhlmann and P. Shapira (eds) (2010), The Theory and Practice of Innovation Policy. An International Handbook, Cheltenham, UK and Northampton, MA, US: Edward Elgar.

Stegmaier, P., S. Kuhlmann and V. R. Visser (2012), 'Governance of the discontinuation of socio-technical systems', paper presented at the Jean Monnet Conference: The Governance of Innovation and Socio-Technical Systems in Europe: New Trends, New Challenges, International Workshop, Copenhagen Business School, Denmark, 1-2 March 2012.

Stegmaier, P. (2009), Wissen, was Recht ist. Richterliche Rechtspraxis aus wissenssoziologisch-ethnografischer Sicht, Wiesbaden: VS

Strauss, A. (1993), Continual permutations of action, New York: Aldine de Gruyter

Streeck, W. and K. Thelen (eds) (2005), Beyond Continuity: Institutional Change in Advanced Political Economies, Oxford: Oxford University Press.

Turnheim, B. and F. W. Geels (2012), 'Regime destabilisation as the flipside of energy transitions: Lessons from the history of the British coal industry (1913-1997)', Energy Policy, 50, 35-49.

Utterback, J. (2003), 'The dynamics of innovation in the internet and the university', Aspen Institute Forum 2002, Educause, 81-103, accessed 27 February 2012 at http://net.educause.edu/ir/library/pdf/FFPIU024.pdf.

Visser, V. R. and P. Stegmaier (2014), 'The discontinuation of the incandescent light bulb in the EU', (in preparation).

Visser, V. R. (2012), 'The purposeful governance of technology discontinuation: An explorative study on the discontinuation of the incandescent light bulb in the EU', Enschede, available at Master thesis, http://essay.utwente.nl/61736/.

Vito (2009a), 'Preparatory studies for eco-design requirements of EuPs: Final report Lot 19: Domestic lighting', accessed 22 February 2012 at www. eup4light.net/assets/pdffiles/Final_part1_2/EuP_Domestic_Part1en2_V11.pdf.

Vito (2009b), 'Preparatory Studies for Eco-design Requirements of EuPs: Project Report Lot 19: Domestic lighting', accessed 6 March 2012 at www. eup4light.net/assets/pdffiles/Final_part1_2/EuP_Domestic_Project_report_ V10.pdf.

Weber, M. (1978), Economy and Society. An Outline of Interpretive Sociology, Berkley: University of California Press.

Zucker, L. G. (1991), 'The role of institutionalization in cultural persistence', in W. W. Powell and P. J. DiMaggio (eds), The New Institutionalism in Organization Analysis, Chicago: Chicago University Press, pp. 83-107. 